\title{
Bacterial communities in penile skin, male urethra, and vaginas of heterosexual couples with and without bacterial vaginosis
}

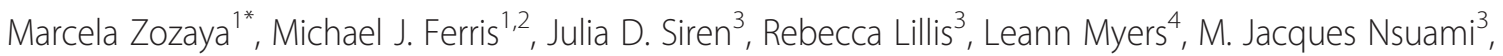 \\ A. Murat Eren ${ }^{5}$, Jonathan Brown ${ }^{6}$, Christopher M. Taylor ${ }^{7}$ and David H. Martin ${ }^{3,7^{*}}$
}

\begin{abstract}
Background: The epidemiology of bacterial vaginosis (BV) suggests it is sexually transmissible, yet no transmissible agent has been identified. It is probable that BV-associated bacterial communities are transferred from male to female partners during intercourse; however, the microbiota of sexual partners has not been well-studied.

Results: Pyrosequencing analysis of PCR-amplified $16 \mathrm{~S}$ rDNA was used to examine BV-associated bacteria in monogamous couples with and without BV using vaginal, male urethral, and penile skin specimens. The penile skin and urethral microbiota of male partners of women with BV was significantly more similar to the vaginal microbiota of their female partner compared to the vaginal microbiota of non-partner women with BV. This was not the case for male partners of women with normal vaginal microbiota. Specific BV-associated species were concordant in women with BV and their male partners.

Conclusions: In monogamous heterosexual couples in which the woman has BV, the significantly higher similarity between the vaginal microbiota and the penile skin and urethral microbiota of the male partner, supports the hypothesis that sexual exchange of BV-associated bacterial taxa is common.
\end{abstract}

Keywords: Bacterial vaginosis, Microbiome, Sexual transmission, Penile skin, Urethra, Vagina

\section{Background}

Bacterial vaginosis (BV) is a leading cause of vaginal infection [1] and the condition is associated with serious sequelae including increased risk of HIV transmission [24], adverse pregnancy outcomes [5-7], and acquisition of sexually transmitted infections (STIs) [8]. Moreover, antibiotic treatment success rates are low and recurrence rates are high [9-11]. BV is currently thought to be due to an ecological imbalance in the composition of the vaginal microbiota rather than a classic infection caused by a specific pathogen. BV is characterized by a decrease in the abundance of vaginal Lactobacillus species, which are

\footnotetext{
* Correspondence: hinchliffe_mz@jpso.com; dhmartin@lsuhsc.edu

'Children's Hospital of New Orleans, 200 Henry Clay Ave., New Orleans, LA 70118, USA

${ }^{3}$ Department of Internal Medicine, Louisiana State University Health Sciences Center, 1542 Tulane Ave., New Orleans, LA 70112, USA

Full list of author information is available at the end of the article
}

generally regarded as beneficial, and an increase in nonLactobacillus species that include Gardnerella vaginalis, Atopobium vaginae, Megasphaera spp., Sneathia spp., Prevotella spp., and many others [12-21]. Over the past decade, studies using genetic sequencing analysis of $16 \mathrm{~S}$ rRNA genes PCR-amplified from vaginal DNA specimens have dramatically increased the number of bacterial species known to inhabit the vaginal environment, many of which have been shown to be highly associated with BV [12-21].

Despite decades of study and considerable evidence suggesting that BV may be sexually transmitted, this hypothesis has not been accepted universally [22-25]. The most direct evidence for sexual transmission comes from a study of healthy women who developed BV after being inoculated with vaginal secretions from women with BV [26]. Studies of lesbian women also suggest that exchange of vaginal secretions during sexual encounters 
transmits BV [27]. Large studies of young sexually experienced and inexperienced women have shown that BV is uncommon in inexperienced women $[28,29]$ and that $\mathrm{BV}$-associated bacteria are absent or rare in sexually unexposed women [30]. Additionally, there is evidence that shows an epidemiological association between heterosexual intercourse and BV [31,32]. Moreover, G. vaginalis and other potential BV-causative bacteria can be cultivated from the male urethra, the glans penis, the coronal sulcus, and the prepuce [33, 34]. Recent studies employing cultivation-independent analyses confirm that many BV-associated species can also be detected in male penile skin, semen, urethral, and urine specimens [35-39]. A recent paper [40] shows that among uncircumcised males, the presence of BV-like flora in the coronal sulcus skin specimens correlates with BV diagnosed by the Nugent score in their sex partners. Based on these studies and our previous study which showed a high degree of similarity between G. vaginalis oligotypes in heterosexual couples [41], it seems probable that sexual exchange of BV-associated bacteria between male and female partners does occur. Such an exchange could potentially induce a change in the composition and abundance of vaginal species leading to BV. Here, we use a pyrosequencing analysis of $16 \mathrm{~S}$ rRNA genes to examine the diversity, community composition, prevalence, and relative abundance of genital bacteria in monogamous couples. Clinical samples included vaginal specimens of women with Nugent and Amsel score-defined BV and normal vaginal microbiota, as well as penile skin and urethral specimens of their male sexual partners.

\section{Results}

\section{Patient population, behavioral and sexually transmitted} infection risk factors

The mean age of men and women in the BV-couples group (BV-couples) was 30.7 years for men (SD+/-9.6) and 27.6 years for women $(\mathrm{SD}+/-6.9)$. The mean age of men and women in the normal-couples group (normalcouples) was similar to that of the BV-couples (Table 1). The study population was predominantly AfricanAmerican in both the normal and BV-couples. Based on independent reporting, the mean duration of the relationship between couples ranged from 39.8 to 46.9 months, and this interval did not differ significantly between BV and normal-couples. A past history of STIs, and other STI risk factors, did not differ between normal and BV-couples. Only $54 \%$ of men in the BV-couples group (BV-males) were circumcised, compared to $74 \%$ of men in the normal-couples group (normalmales) $(P=0.057)$.

Women in the BV-couples group (BV-women) were more likely to report a past diagnosis of $\mathrm{BV}$ compared to women in the normal-couples group (normal-women) ( 80 vs. $58 \%, P=0.024$ ) (Table 2). The mean Amsel score was 3.64 (SD+/-0.764) for BV-women and 0.28 $(\mathrm{SD}+/-0.797)$ for normal-women. Consistent with the diagnosis of BV, significantly more BV-women complained of vaginal discharge and odor (68 and $72 \%$, respectively) compared to normal-women. BV-women were found to have significantly higher amounts of vaginal secretions on examination compared to normal-women. None of the other variables measured differed between BV and normal-women (Table 2). Additional file 1: Table S1 and Additional file 2: Table S2 show the metadata used to perform these analyses.

\section{Bacterial diversity in normal and BV specimens}

As expected, the vaginal bacterial diversity of BV-women was significantly higher than that of normal-women, irrespective of the diversity metric used $(P=0.001)$ (Table 3$)$. Likewise, the penile skin diversity of BV-males was significantly higher $(P \leq 0.038)$ than that of normal-males. However, the difference in penile skin bacterial diversity between BV-males and normal-males was not as great as the difference observed between BV-women and normalwomen. In contrast to penile skin and vaginal specimens, the bacterial diversity of urethral specimens did not differ between BV and normal-males (Table 3).

The relative abundance of BV-associated bacteria was significantly higher in women with BV compared to normal-women (Additional file 3: Table S3). Moreover, many of these BV-associated bacteria were significantly more abundant in penile skin specimens and urethral specimens of BV-males, compared to normal-males.

\section{Effect of monogamous sexual partnerships on genital bacterial community composition}

We examined the influence of monogamous sexual partnerships on the composition of genital microbiota within couples (Fig. 1). The results showed that in the case of BV-couples, the penile skin communities of BV-males were significantly more similar to the vaginal communities of their sexual partner, compared to the other (non-partner) women in the study. This was true regardless of whether the BV-males were circumcised $(P=0.0018)$ or uncircumcised $(P=0.0027)$ (Fig. 1a). In the case of BV male urethral specimens, only the microbiota of uncircumcised BV-males was significantly more similar to the vaginal microbiota of their partner $(P=0.0015)$ (Fig. 1). Finally, among normal-couples, neither the penile skin nor the male urethral microbiota were more similar among sexual partners compared to non-partners (Fig. 1b).

Principal coordinate analyses showed no clear separation between the penile skin microbiota of circumcised 
Table 1 Demographics and STI risk factors in couples in which the female does or does not have bacterial vaginosis (BV)

\begin{tabular}{|c|c|c|c|c|c|c|}
\hline & \multicolumn{3}{|l|}{ Women } & \multicolumn{3}{|l|}{ Men } \\
\hline & $\mathrm{BV}(n=65)$ & Normal $(n=31)$ & $P$ value $^{a}$ & $\mathrm{BV}(n=65)$ & Normal $(n=65)$ & $P$ value $^{a}$ \\
\hline Mean age, years $\pm S D$ & $27.3 \pm 6.6$ & $28.4 \pm 7.7$ & 0.473 & $30.0 \pm 8.4$ & $32.2 \pm 12.0$ & 0.295 \\
\hline African-American, $n$ (\%) & 57 (88 \%) & $22(71 \%)$ & 0.045 & $55(85 \%)$ & $24(77 \%)$ & 0.388 \\
\hline Married, $n(\%)$ & $10(15 \%)$ & $5(16 \%)$ & 0.688 & $10(15 \%)$ & $5(16 \%)$ & 0.451 \\
\hline \multicolumn{7}{|l|}{ History of STD } \\
\hline Gonorrhea, $n(\%)$ & $17(26 \%)$ & $7(23 \%)$ & 0.705 & 17 (26 \%) & $8(26 \%)$ & 0.971 \\
\hline Chlamydia, $n(\%)$ & $29(45 \%)$ & $8(26 \%)$ & 0.077 & $20(31 \%)$ & $6(19 \%)$ & 0.239 \\
\hline Trichomonas, n (\%) & $19(29 \%)$ & $9(29 \%)$ & 0.984 & $2(3 \%)$ & $1(3 \%)$ & 0.969 \\
\hline \multicolumn{7}{|l|}{ Number of sex partners } \\
\hline$\geq 2$ in last 12 months, $n(\%)$ & $27(42 \%)$ & 12 (39\%) & 0.792 & $34(52 \%)$ & $18(58 \%)$ & 0.597 \\
\hline$\geq 2$ in last 60 days, $n(\%)$ & $2(3 \%)$ & $2(7 \%)$ & 0.592 & $5(8 \%)$ & $4(13 \%)$ & 0.413 \\
\hline Mean duration of partnership ${ }^{b}$, months & 39.8 & 44.7 & 0.654 & 46.9 & 46.3 & 0.963 \\
\hline \multicolumn{7}{|l|}{ Mean number of sexual acts/month ${ }^{b}$} \\
\hline Vaginal intercourse & 11.3 & 12.0 & 0.683 & 11.9 & 14.3 & 0.406 \\
\hline Received oral sex & 6.0 & 5.0 & 0.581 & 5.7 & 7.7 & 0.477 \\
\hline Performed oral sex & 4.5 & 4.7 & 0.920 & 4.8 & 7.6 & 0.294 \\
\hline Anal intercourse in last month, $n(\%)$ & $12(19 \%)$ & $5(17 \%)$ & 0.832 & $10(16 \%)$ & $3(10 \%)$ & 0.535 \\
\hline Never or rarely use condoms ${ }^{b}, n(\%)$ & $44(68 \%)$ & 19 (61 \%) & 0.683 & $40(62 \%)$ & $20(65 \%)$ & 0.935 \\
\hline Circumcised, $n(\%)$ & - & - & - & $35(54 \%)$ & $23(74 \%)$ & 0.057 \\
\hline
\end{tabular}

${ }^{a} P$ values are by Pearson's chi-square of Fisher's Exact tests for categorical variables and by $t$ tests for continuous variables

${ }^{\mathrm{b}}$ With enrolled partner

SD standard deviation, STD sexually transmitted disease

and uncircumcised men, for both BV-males and normalmales (Fig. 2).

\section{Correlation between vaginal OTUs and penile skin and urethral OTUs of sexual partners}

Spearman correlation coefficients were used to investigate associations between the most common OTUs in the vagina of BV-women and normal-women and the same OTUs in the penile skin and urethral specimens of their sexual partners (Tables 4 and 5). The majority of OTUs in vaginal and penile skin specimens of BV-couples showed a strong positive correlation. Correlations were only modestly weaker between vaginal and male urethral specimens in the BV-couples. In contrast, correlations among normal-couples were strikingly lower.

\section{Discussion}

While it is well-recognized that BV is associated with sexual activity, few studies provide evidence that BVassociated taxa are transferred during sexual intercourse. A notable outcome of our study, that is consistent with sexual exchange of BV-associated taxa, is that the penile skin microbiota of male partners of women with BV were more similar to the vaginal microbiota of their sexual partner compared to non-partner women who also had BV (Fig. 1). The data for BV-couples indicate that monogamous sexual intercourse, as defined in this study between a male partner and a female partner who has BV, has a homogenizing influence on the genital microbiota of the couple such that the genital microbiota of BV-couples become more similar over time. These results extend the data of Liu et al. [40] who have shown that BV-associated organisms are significantly increased in penile skin of BVmales. Taken together, the data from these two studies strongly support the hypothesis that BV-associated bacteria are sexually transmitted. Moreover, there appeared to be no influence of male circumcision on our findings, as the penile skin microbiota of both circumcised and uncircumcised BV-males was significantly more similar among sexual partners compared to non-partners. In contrast, no similar relationship was found in normal-couples, in either the penile skin or male urethral specimens. The reasons for the lack of significant similarity between normalcouples is unclear. However it seems likely that the high degree of similarity among the vaginal microbiota of normal-women, often predominated by one or two Lactobacillus species, such as $L$. iners or $L$. crispatus, decreases the discriminatory power of the analysis. Another possible explanation is that the predominant vaginal bacterial species in normal-women do not persist for an extended period of time in the environment of the penile skin or the male urethra. 
Table 2 Medical histories and clinical findings in BV and normal-women

\begin{tabular}{|c|c|c|c|}
\hline & \multicolumn{3}{|l|}{ Women } \\
\hline & $\mathrm{BV}(n=65)$ & Normal $(n=31)$ & $P$ value $^{a}$ \\
\hline Past history of BV, $n(\%)$ & $52(80 \%)$ & $18(58 \%)$ & 0.024 \\
\hline Mean months since last episode of BV & 9.7 & 5.9 & 0.332 \\
\hline History of douching, $n(\%)$ & $22(34 \%)$ & $9(30 \%)^{b}$ & 0.710 \\
\hline History of vaginal products or medications used, $n(\%)$ & $13(20 \%)$ & $9(29 \%)$ & 0.345 \\
\hline Use of birth control, $n(\%)$ & $26(40 \%)$ & $14(45 \%)$ & 0.631 \\
\hline Mean number of days since beginning of last menstrual period & 25.7 & 23.5 & 0.824 \\
\hline \multicolumn{4}{|l|}{ Symptoms } \\
\hline Vaginal discharge, $n(\%)$ & $44(68 \%)$ & $12(39 \%)$ & 0.007 \\
\hline Vaginal odor, $n(\%)$ & 47 (72 \%) & $7(23 \%)$ & $<0.0001$ \\
\hline Vaginal irritation, $n(\%)$ & 17 (26 \%) & $5(16 \%)$ & 0.275 \\
\hline \multicolumn{4}{|l|}{ Amount of discharge on examination } \\
\hline None, scant, $n(\%)$ & $24(38 \%)$ & $25(81 \%)$ & $<0.0001$ \\
\hline Moderate, $n(\%)$ & $31(48 \%)$ & $6(19 \%)$ & \\
\hline Copious, n (\%) & $9(14 \%)$ & $0(0 \%)$ & \\
\hline Mean Amsel score & 3.64 & 0.28 & $<0.0001$ \\
\hline Mean Nugent score & 8.75 & 0.87 & $<0.0001$ \\
\hline
\end{tabular}

${ }^{a} P$ values are by Pearson's chi-square for categorical variables and by $t$ tests for continuous variables

${ }^{\mathrm{b}}$ Calculation based on $n=30$

Two longitudinal $16 \mathrm{~S}$ rDNA-based studies have shown that circumcision significantly alters the composition of penile skin microbiota in paired specimens, collected preand post-circumcision $[38,42]$. In contrast, we did not observe a significant difference in UniFrac distances of microbial communities in circumcised and uncircumcised male penile skin specimens, within either the normal male group or the BV male groups (Fig. 2). Significant differences in study design, study populations, sampling protocols, and analysis methods preclude direct comparisons of our results with those of Price et al. [38] and Liu et al. studies [42]. Price and Liu performed longitudinal studies comparing penile skin specimens before and (1 year) after circumcision, whereas ours was a cross-sectional study comparing groups of circumcised and uncircumcised men. In addition to study design, the characteristics of the female partners also differed between our study and those of Price and Liu [43]. Only $30 \%$ of the regular sex partners of men in the Price and Liu studies had BV by the Nugent criteria [43]. Thus, over the 1-year observation period following circumcision, most of these men were not being continuously exposed to BV and many appear to have lost the bacteria which comprise BV-like microbiomes. In contrast, all of the BV men in our study were having concurrent intercourse with women who had BV. Thus, under this distinctly different condition, our data show that penile skin microbiomes do not differ between men based on circumcision status. Future prospective

Table 3 Microbial diversity of normal and BV vaginal, penile skin, and urethral specimens

\begin{tabular}{|c|c|c|c|c|c|}
\hline Specimen type & Diversity estimator & BV mean (SD) & Normal mean (SD) & $t$ stat & $P$ value \\
\hline Vaginal & Chao1 & $27.4(9.3)$ & $11.8(5.9)$ & 8.475 & 0.001 \\
\hline Vaginal & Observed species & $23.2(7.8)$ & $9.6(3.5)$ & 9.191 & 0.001 \\
\hline Vaginal & PD whole tree & $3.1(0.7)$ & $1.4(0.6)$ & 12.115 & 0.001 \\
\hline Penile skin & Chao1 & $38.5(14.7)$ & $31.1(11.3)$ & 2.189 & 0.038 \\
\hline Penile skin & Observed species & $28.3(10.4)$ & $23.2(7.5)$ & 2.171 & 0.032 \\
\hline Penile skin & PD whole tree & $2.8(0.9)$ & $2.3(0.8)$ & 2.284 & 0.018 \\
\hline Male urethra & Chao1 & $34.7(26.3)$ & $34.7(25.3)$ & 0.007 & 0.995 \\
\hline Male urethra & Observed species & $24.6(17.7)$ & $26.9(21.4)$ & -0.530 & 0.590 \\
\hline Male urethra & PD whole tree & $3.0(1.5)$ & $3.0(1.7)$ & 0.015 & 0.987 \\
\hline
\end{tabular}

SD standard deviation 


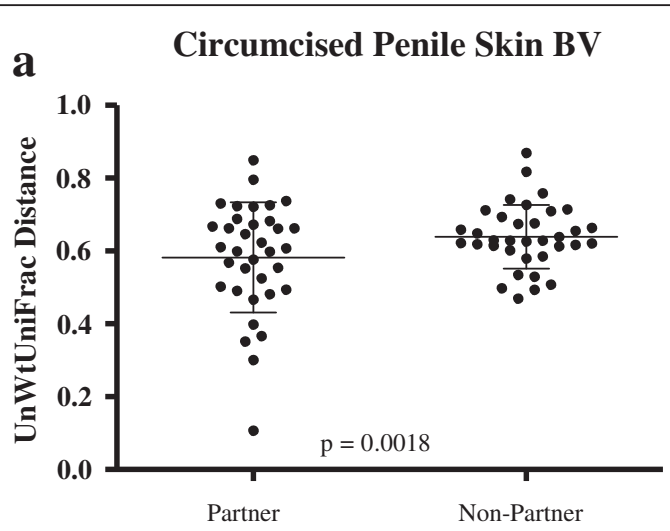

Circumcised Urethra BV

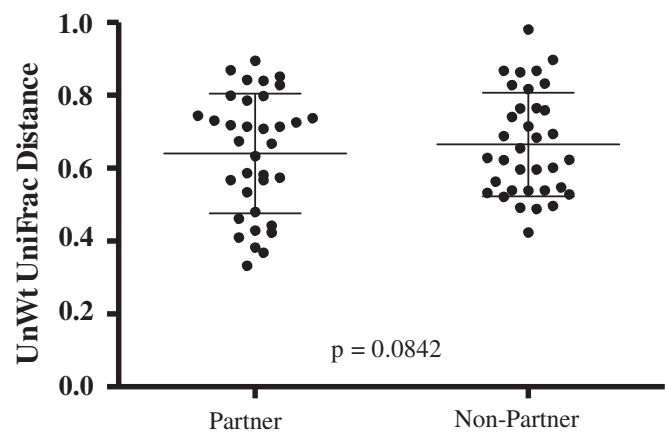

b Circumcised Penile Skin Normal

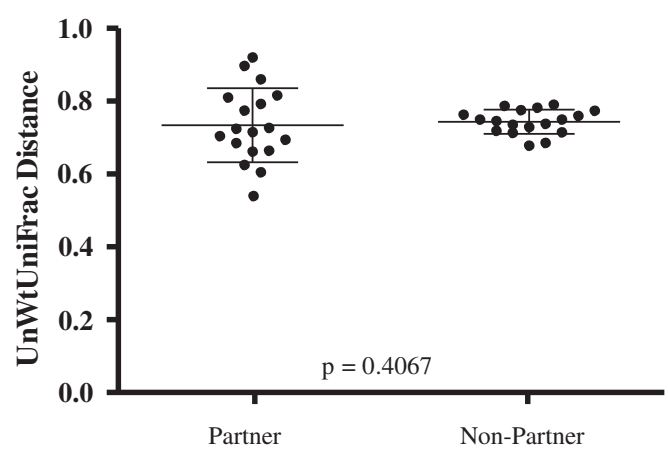

Circumcised Urethra Normal

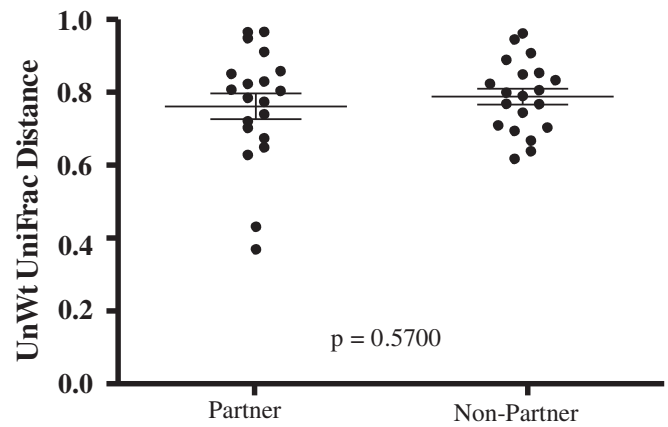

Uncircumcised Penile Skin BV

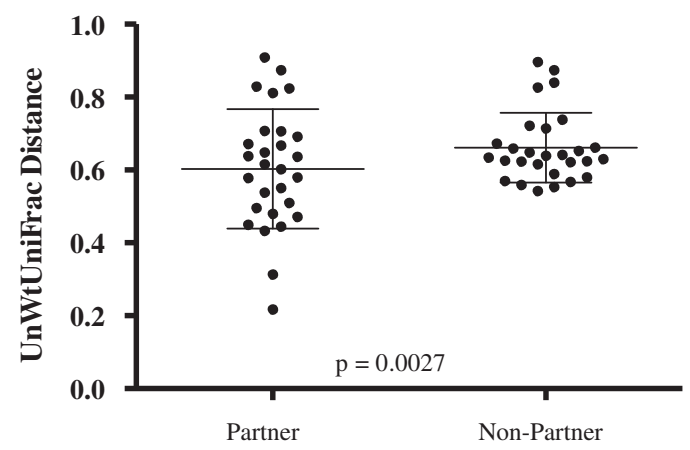

Uncircumcised Urethra BV

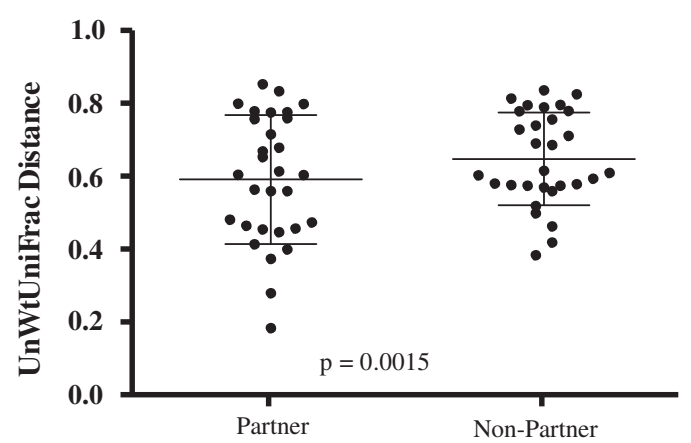

Uncircumcised Penile Skin Normal

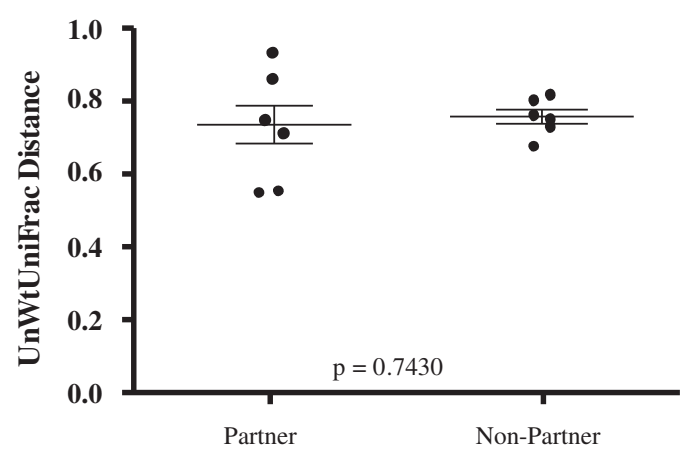

Uncircumcised Urethra Normal

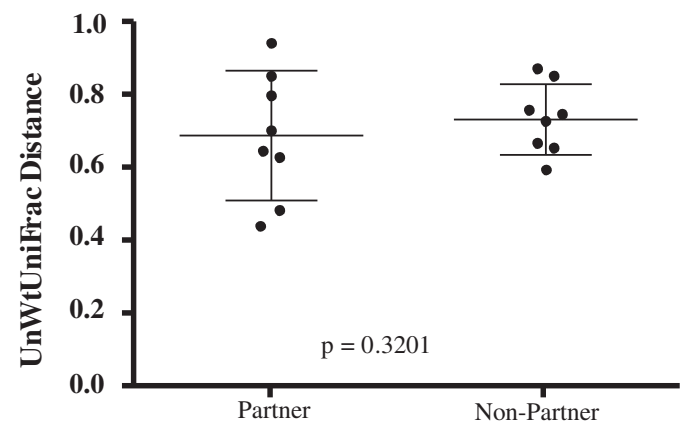

Fig. 1 Comparison of unweighted UniFrac distances between the microbiota of sexual partners and non-partners. a BV-couples and $\mathbf{b}$ normal-couples. The analyses were stratified by the circumcision status of the male partners and include penile skin and male urethral specimens as indicated. $P$ values are from paired $t$ tests 


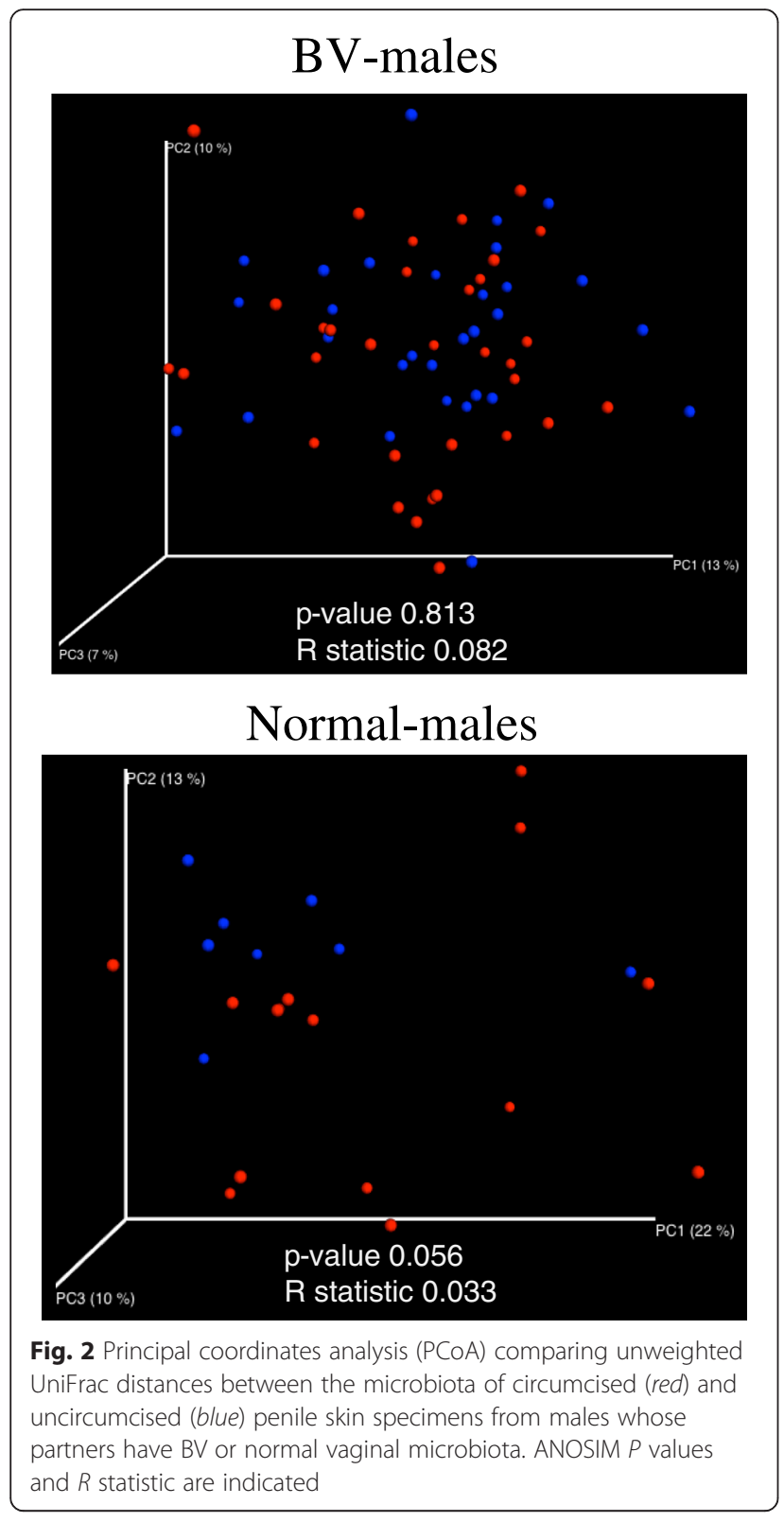

studies of male partners of women with BV, following successful treatment of the female partner, could be performed to test the hypothesis that circumcised men clear their penile skin of BV-like microbiomes more rapidly than uncircumcised men.

\section{Conclusions}

In summary, we found that the penile skin of male partners of women with BV is colonized by many of the same bacterial taxa that are strongly associated with BV. More significantly, we found that the penile skin bacterial communities of male partners of women with BV were significantly more similar to the vaginal communities of their partner's than to vaginal communities of other BV- women in the study, which strongly suggests that sexual transmission of BV-associated bacteria is a common occurrence. Urethral communities of male BVpartners were similarly related to the vaginal communities of their partners, though it is unclear how contamination of the male urethral swab specimen by penile skin organisms may have influenced this finding. The same similarity between genital microbiota of sexual partners was not seen in couples without BV. Taken together, these findings support the hypotheses that BV-associated bacteria are exchanged during sex and that male carriage of these organisms could contribute to relapses of clinical BV following treatment, and could be the cause of incident BV infection in previously unexposed women.

\section{Methods}

Ethics statement

All patients enrolled in this study gave written informed consent to their participation. The study protocol and consent form was approved by the LSU Health Sciences Center Institutional Review Board.

\section{Sample collection and clinical measurements}

Couples enrolled in this study were recruited at the New Orleans sexually transmitted disease (STD) clinic. Couples in which the female had BV (BV-couples) were part of a larger cohort study designed to determine the role of genital tract microbiomes on BV treatment failure and relapse following treatment. Data presented here are from the enrollment visit only. Couples in which the female did not have BV (normal-couples) were recruited for the analyses presented here concerning the relationships between male and female partner microbiomes. All women were $\geq 18$ years of age and attended the STD clinic with a partner with whom they had a monogamous sexual relationship for at least 1 month. The exclusion criteria included antibiotic use within the last 28 days, pregnancy, HIV infection, and any concurrent infection requiring either member of the couple to take antibiotics. Five vaginal swabs were collected from each woman: one for wet prep, $\mathrm{KOH}$, and $\mathrm{pH}$, one for Gram staining, one for Trichomonas culture, one for DNA extraction, and one for back-up. A urethral swab and two penile skin swabs were obtained from each male. The penile skin swabs were obtained by swabbing the glans, the coronal sulcus, and the shaft of the penis. The male swabs and the vaginal swabs intended for DNA extraction were placed in tubes containing the AssayAssure $^{\mathrm{Tm}}$ nucleic acid preservation media (Thermoscientific, Pittsburg, PA). Details on sample collection have been described previously [41]. The female specimens were characterized clinically for BV using Amsel criteria [31] and Nugent scores [44]. For the purpose of this study, the definition of $\mathrm{BV}$ required that the woman had a 
Table 4 Correlation of specific OTUs* between vagina, penile skin, and male urethra from BV-couples

\begin{tabular}{|c|c|c|c|c|c|c|c|}
\hline & \multicolumn{2}{|c|}{ VG/PS ${ }^{2}$} & \multicolumn{2}{|c|}{ VG/UT ${ }^{3}$} & \multirow{9}{*}{$\begin{array}{r}\text { rho } \\
1.00 \\
0.80 \\
0.60 \\
0.40 \\
0.20 \\
0.00 \\
-0.20 \\
-0.40 \\
-0.60 \\
-0.80 \\
-1.00 \\
\end{array}$} & \multirow{9}{*}{$\stackrel{\downarrow}{\uparrow}$} & \multirow{9}{*}{$\begin{array}{l}\text { Very Strong } \\
\text { Moderate } \\
\text { Negligible } \\
\text { Moderate } \\
\text { Very strong }\end{array}$} \\
\hline OTU & rho $^{l}$ & $\mathrm{P}$ value & rho $^{l}$ & $\mathrm{P}$ value & & & \\
\hline Megasphaera2 & 0.549 & $<0.0001$ & 0.085 & 0.5036 & & & \\
\hline Pv.123-f2-42 & 0.537 & $<0.0001$ & 0.584 & $<0.0001$ & & & \\
\hline Pv.123-f-110 & 0.482 & $<0.0001$ & 0.448 & 0.0001 & & & \\
\hline BVAB1 & 0.477 & $<0.0001$ & 0.153 & 0.2235 & & & \\
\hline P. bivia & 0.422 & 0.0004 & 0.510 & $<0.0001$ & & & \\
\hline Prevotella & 0.421 & 0.0004 & 0.402 & 0.0008 & & & \\
\hline Gardnerella & 0.419 & 0.0004 & 0.324 & 0.0082 & & & \\
\hline Aerococcus & 0.413 & 0.0005 & 0.421 & 0.0004 & & & \\
\hline Pv.123-b-95 & 0.411 & 0.0006 & 0.239 & 0.0546 & & & \\
\hline L. iners & 0.399 & 0.0009 & 0.215 & 0.0856 & & & \\
\hline Porphyromonas & 0.399 & 0.0009 & 0.105 & 0.4077 & & & \\
\hline Sneathia & 0.376 & 0.0019 & 0.258 & 0.0376 & & & \\
\hline Leptotrichia & 0.371 & 0.0021 & 0.376 & 0.0019 & & & \\
\hline Pv.112Q-3 & 0.360 & 0.0030 & 0.451 & 0.0001 & & & \\
\hline Pv.123b-5 & 0.360 & 0.0030 & 0.347 & 0.0043 & & & \\
\hline Pv.136-b-40 & 0.354 & 0.0036 & 0.101 & 0.4267 & & & \\
\hline Pv.123-f-82 & 0.354 & 0.0036 & 0.352 & 0.0038 & & & \\
\hline Atopobium & 0.353 & 0.0036 & 0.202 & 0.1071 & & & \\
\hline Actinomyces & 0.344 & 0.0048 & 0.229 & 0.0664 & & & \\
\hline Megasphaeral & 0.328 & 0.0073 & 0.327 & 0.0074 & & & \\
\hline Pv.113s1-20 & 0.324 & 0.0081 & 0.405 & 0.0007 & & & \\
\hline Pv.123-b-46 & 0.311 & 0.0113 & 0.309 & 0.012 & & & \\
\hline Eggerthella & 0.305 & 0.0091 & 0.164 & 0.0132 & & & \\
\hline Anaerococcus & 0.288 & 0.0198 & 0.247 & 0.0471 & & & \\
\hline Dialister & 0.264 & 0.0014 & 0.197 & 0.0336 & & & \\
\hline BVAB2 & 0.263 & 0.0338 & 0.048 & 0.7031 & & & \\
\hline M. hominis & 0.258 & 0.0375 & 0.400 & 0.0009 & & & \\
\hline Pv.123f2-17 & 0.230 & 0.0652 & 0.199 & 0.1123 & & & \\
\hline Peptoniphilus & 0.219 & 0.0800 & 0.280 & 0.0236 & & & \\
\hline Lactobacillus sp. & 0.212 & 0.0896 & 0.420 & 0.0004 & & & \\
\hline Barnesiella & 0.168 & 0.1808 & 0.118 & 0.3493 & & & \\
\hline Gemella & 0.150 & 0.2342 & 0.216 & 0.0836 & & & \\
\hline Peptostreptococcus & 0.138 & 0.2756 & 0.075 & 0.5546 & & & \\
\hline Parvimonas & 0.117 & 0.3568 & -0.016 & 0.8977 & & & \\
\hline P. disiens & 0.049 & 0.7002 & 0.064 & 0.6160 & & & \\
\hline Pv.123f3-83 & -0.060 & 0.6360 & -0.068 & 0.5940 & & & \\
\hline
\end{tabular}

'Spearman correlation coefficient. The gradient bar on the right shows the strength of the correlations Positive correlations (red); negative correlations (green)

${ }^{2}$ Associations between vagina (VG) and penile skin (PS)

${ }^{3}$ Associations between vagina and male urethra (UT)

*Only those vaginal OTUs which had a prevalence of $\geq 30 \%$ among BV-women were included in this analysis

Nugent score of $7-10$, and the definition of a normal woman was a Nugent score of $0-3$. Based on these criteria, 96 couples were available for analysis including 65 in which the woman had BV and 31 in which the woman was normal. From these, 283 samples were available for analysis (96 vaginal, 94 urethral, and 93 penile skin). We use the terms BV-partners and normal partners to refer to males whose partners had BV and normal vaginal microbiota, respectively.

\section{Molecular methods}

DNA extraction was performed using the QIAamp DNA mini kit (vaginal swabs) and QIAamp DNA micro kit (male specimens) (Qiagen Inc., Valencia, CA) according to the manufacturer's instructions. An initial lysis step with $20 \mathrm{mg}$ per milliliter lysozyme was included to improve DNA extraction from Gram-positive bacteria. The DNA obtained from the two penile skin swabs was combined to increase the yield. Bacterial tag-encoded FLX amplicon 
Table 5 Correlation of specific OTUs* between vagina, penile skin and male urethra from normal-couples

\begin{tabular}{|c|c|c|c|c|}
\hline & \multicolumn{2}{|c|}{$\mathrm{VG} \mathrm{PS}^{2}$} & \multicolumn{2}{|c|}{$\mathrm{VG} / \mathrm{UT}^{3}$} \\
\hline OTU & rho $^{l}$ & $\mathrm{P}$ value & rho $^{l}$ & $\mathrm{P}$ value \\
\hline Pv.123-f-82 & 0.504 & 0.0056 & -0.033 & 0.8672 \\
\hline Dialister & 0.443 & 0.0174 & 0.240 & 0.2121 \\
\hline L. crispatus & 0.391 & 0.0390 & -0.084 & 0.6682 \\
\hline L. jensenii & 0.384 & 0.0428 & -0.259 & 0.1770 \\
\hline Lactobacillus sp. & 0.327 & 0.0891 & 0.284 & 0.1359 \\
\hline Pv.123-b-46 & 0.280 & 0.1502 & 0.379 & 0.0420 \\
\hline Streptococcus & 0.221 & 0.2608 & 0.179 & 0.3568 \\
\hline U. urealythicum & 0.156 & 0.4311 & -0.071 & 0.7180 \\
\hline L. helveticus & 0.142 & 0.4734 & 0.223 & 0.2479 \\
\hline L. gasseri & 0.125 & 0.5296 & -0.133 & 0.4945 \\
\hline Peptoniphilus & 0.049 & 0.8075 & -0.023 & 0.9056 \\
\hline Gardnerella & 0.034 & 0.8635 & -0.146 & 0.4535 \\
\hline L. iners & -0.020 & 0.9209 & 0.043 & 0.8257 \\
\hline Corynebacterium & -0.065 & 0.7461 & -0.375 & 0.0446 \\
\hline
\end{tabular}

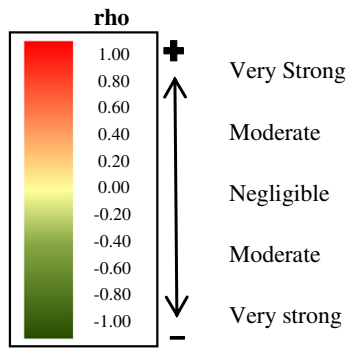

${ }^{1}$ Spearman correlation coefficient. The gradient bar on the right shows the strength of the correlations

Positive correlations (red); negative correlations (green)

${ }^{2}$ Associations between vagina (VG) and penile skin (PS)

${ }^{3}$ Associations between vagina and male urethra (UT)

*Only those vaginal OTUs which had a prevalence of $\geq 30 \%$ among normal-women were included in this analysis

pyrosequencing analysis of the V4-V6 region of the $16 \mathrm{~S}$ rRNA gene (530 F: GTGCCAGCMGCNGCGG and 1100R: GGGTTNCGNTCGTTG) was performed by a commercial facility (Research and Testing Laboratory, Lubbock, TX).

\section{Data analysis}

Pyrosequencing post-processing was performed by the sequencing facility (http://www.researchandtesting.com/ docs/Data_Analysis_Methodology.pdf). In brief, the data was quality-checked and denoised, including chimera checking. Sequences that were less than 200 bases in length, contained one or more ambiguous bases, had mean quality scores below Q25, or had a homopolymer region longer than six nucleotides were excluded from the analysis. The sequence files and mapping file for all samples have been deposited in Figshare (http://dx.doi.org/ 10.6084/m9.figshare.1321311). Taxonomic identification and data analysis was performed using an "in house" sequence analysis framework [45] and QIIME [46].

A total of 1,556,072 reads (vagina- 581,169 reads; penile skin- 471, 947 reads; urethra- 502,956 reads) with an average length of $455 \pm 85$ bases were obtained after pyrosequencing post-processing. The average number of reads per sample was 6053 (vaginal specimens), 5074 (penile skin specimens), and 5350 (urethral specimens). An initial taxonomic assignment of reads was performed using BLAST [47] at $97 \%$ sequence similarity against a local database. The database contained 283 16S rRNA gene sequences, including sequences previously detected in PCRbased surveys of vaginal specimens [12, 14, 15, 48-51]. The list of sequences and NCBI reference numbers is available as Additional file 4. The reads that fell under the $97 \%$ threshold, and thus were not matched to the local database sequences, were assigned to operational taxonomic units (OTUs) by the Ribosomal Database Project classifier [52] set at $80 \%$ confidence threshold. A total of 70,793 reads (vagina- 16,523 [2.84\%] reads; penile skin13,610 [2.88 \%] reads; urethra- 40,660 [8.08 \%] reads) were below the $80 \%$ confidence threshold for classification at the genus level and were excluded from further analysis. The taxonomic assignments are shown in Additional file 5: Table S4. Differences in the prevalence of individual taxa, between categories of specimens, were analyzed using Fisher's exact test.

Analyses of bacterial diversity, as well as the distance measurements between bacterial communities, were performed using QIIME [46] after normalizing to a common sequencing depth. Diversity was measured using the average of ten random subsamples of each bacterial community and three diversity metrics, chao1, PD whole tree, and total OTUs. Distances between 
bacterial communities were measured using the unweighted UniFrac metric [53]. An unweighted UniFrac distance matrix containing the distance values between all the pairs of specimens in the study was generated using Python scripts within QIIME. To compare the bacterial community distances of sexual partners to the distances of non-partners, the following steps were used: (1) we obtained the UniFrac distance between a man and his sexual partner from the distance matrix. This was referred to as the partner distance; (2) we obtained all the distances between the man in step 1 and each of the other women in the study; (3) we calculated an average value for the distances obtained in step 2 and referred to this value as the non-partner distance; (4) we repeated steps 1, 2, and 3 for every man in the study; (5) we created two columns of paired data, each row containing a distance between a man and his sex-partner, and a distance between that same man and his "non-partner"; (6) we used a paired $t$ test to test the statistical difference between the partner distances and the non-partner distances.

Spearman correlation coefficients were used to assess the correlation of specific organisms at different sites (vaginal, penile skin, and urethra). All organisms present in greater than $30 \%$ of the BV-women and greater than $30 \%$ of the normal-women were separately selected for this analysis. Correlation analyses for vaginal and penile skin and vaginal and urethral specimens were compared using $z$ statistics following Fisher's transformation. All analyses were conducted using SAS version 9.3.

\section{Availability of supporting data}

The sequence files and mapping file for all the samples included in this study have been deposited in Figshare (http://dx.doi.org/10.6084/m9.figshare.1321311).

\section{Additional files}

Additional file 1: Table S1. Metadata from female patients. (XLS $72 \mathrm{~kb}$ )

Additional file 2: Table S2. Metadata from male sexual partners. (XLS 60 kb)

Additional file 3: Table S3. Average percent abundance of selected OTUs in vaginal specimens of BV- and normal-women, and in penile skin and urethral specimens from their sexual partners. (PDF $144 \mathrm{~kb}$ )

Additional file 4: List of 165 rRNA gene sequences included in our local database. (PDF $644 \mathrm{~kb}$ )

Additional file 5: Table S4. Taxonomic assignments of 165 rRNA sequences obtained from penile skin, urethral, and vaginal specimens. (XLSX $445 \mathrm{~kb}$ )

\section{Competing interests}

The authors declare that they have no competing interests.

\section{Authors' contributions}

DHM and MJF conceived and designed the study. JDS and RL helped design the clinical data collection instrument, enrolled the patients, and collected the biological specimens. MZ performed the DNA extractions and sample preparation. MZ, MJN, LM, CMT, MJF, and DHM participated in data analyses. $A M E, C M T$, and JB created our "in house" sequence analysis framework. MZ, $\mathrm{RL}, \mathrm{MJN}, \mathrm{MJF}$, and DHM wrote the manuscript. All authors helped edit and approved the final manuscript.

\section{Authors' information}

MZ's present address: Jefferson Parish Sheriff's Office Regional DNA Laboratory, Harvey, LA.

\section{Acknowledgements}

This work was supported by National Institute of Health Grant R01 Al079071-01A1.

\section{Author details}

${ }^{1}$ Children's Hospital of New Orleans, 200 Henry Clay Ave., New Orleans, LA 70118, USA. ²Department of Pediatrics, Louisiana State University Health Sciences Center, 1901 Perdido St., New Orleans, LA 70112, USA. ${ }^{3}$ Department of Internal Medicine, Louisiana State University Health Sciences Center, 1542 Tulane Ave., New Orleans, LA 70112, USA. ${ }^{4}$ Department of Biostatistics and Bioinformatics, Tulane School of Public Health and Tropical Medicine, 1440 Canal St., New Orleans, LA 70112, USA. ${ }^{5}$ Marine Biological Laboratory, JBPC, 7 MBL St., Woods Hole, MA 02543, USA. ${ }^{6}$ Rally Software, 3333 Walnut St., Boulder, CO 80301, USA. ${ }^{7}$ Department of Microbiology Immunology and Parasitology, Louisiana State University Health Sciences Center, 1901 Perdido St., New Orleans, LA 70112, USA

Received: 19 February 2015 Accepted: 17 March 2016

Published online: 19 April 2016

\section{References}

1. Hillier SL, Marrazzo JM, Holmes KK. Bacterial vaginosis. In: Holmes KK, Sparling PF, Stamm WE, Piot P, Wasserheit JN, Corey L, Cohen MS, Watts $\mathrm{DH}$, editors. Sexually transmitted diseases. 4th ed. New York: McGraw-Hill; 2008. p. 737-68.

2. Cohen CR, Lingappa JR, Baeten JM, Ngayo MO, Spiegel CA, Hong T, et al. Bacterial vaginosis associated with increased risk of female-to-male HIV-1 transmission: a prospective cohort analysis among African couples. PLoS Med. 2012;9(6):e1001251. doi:10.1371/journal.pmed.1001251.

3. Cu-Uvin S, Hogan JW, Caliendo AM, Harwell J, Mayer KH, Carpenter CC. Association between bacterial vaginosis and expression of human immunodeficiency virus type 1 RNA in the female genital tract. Clin Infect Dis. 2001;33:894-6.

4. Sha BE, Zariffard MR, Wang QJ, Chen HY, Bremer J, Cohen MH, et al. Female genital-tract HIV load correlates inversely with Lactobacillus species but positively with bacterial vaginosis and Mycoplasma hominis. J Infect Dis. 2005;191:25-32.

5. Hill GB. Preterm birth: associations with genital and possibly oral microflora. Ann Periodontol. 1998;3:222-32.

6. Meis PJ, Goldenberg RL, Mercer B, Moawad A, Das A, McNellis D, et al. The preterm prediction study: significance of vaginal infections. National Institute of Child Health and Human Development Maternal-Fetal Medicine Units Network. Am J Obstet Gynecol. 1995;173:1231-5.

7. Onderdonk AB, Lee ML, Lieberman E, Delaney ML, Tuomala RE. Quantitative microbiologic models for preterm delivery. J Clin Microbiol. 2003:41:1073-9.

8. Brotman RM, Klebanoff MA, Nansel TR, Yu KF, Andrews WW, Zhang J, et al. Bacterial vaginosis assessed by gram stain and diminished colonization resistance to incident gonococcal, chlamydial, and trichomonal genital infection. J Infect Dis. 2010:202:1907-15.

9. Hanson JM, McGregor JA, Hillier SL, Eschenbach DA, Kreutner AK, Galask RP, et al. Metronidazole for bacterial vaginosis. A comparison of vaginal gel vs. oral therapy. J Reprod Med. 2000;45(11):889-96.

10. Livengood CH, McGregor JA, Soper DE, Newton E, Thomason JL. Bacterial vaginosis: efficacy and safety of intravaginal metronidazole treatment. Am J Obstet Gynecol. 1994;170:759-64.

11. Hillier SL, Lipinski C, Briselden AM, Eschenbach DA. Efficacy of intravaginal 0. $75 \%$ metronidazole gel for the treatment of bacterial vaginosis. Obstet Gynecol. 1993:81:963-7.

12. Hyman RW, Fukushima M, Diamond L, Kumm J, Giudice LC, Davis RW. Microbes on the human vaginal epithelium. Proc Natl Acad Sci U S A. 2005;102:7952-7. 
13. Verhelst $R$, Verstraelen $H$, Claeys $G$, Verschraegen $G$, Delanghe J, Van Simaey $L_{\text {, et }}$ al. Cloning of $16 \mathrm{~S}$ rRNA genes amplified from normal and disturbed vaginal microflora suggests a strong association between Atopobium vaginae, Gardnerella vaginalis and bacterial vaginosis. BMC Microbiol. 2004:4:16.

14. Zhou X, Brown CJ, Abdo Z, Davis CC, Hansmann MA, Joyce P, et al. Differences in the composition of vaginal microbial communities found in healthy Caucasian and black women. ISME J. 2007;1:121-33.

15. Oakley BB, Fiedler TL, Marrazzo JM, Fredricks DN. Diversity of human vaginal bacterial communities and associations with clinically defined bacterial vaginosis. Appl Environ Microbiol. 2008;74:4898-909.

16. Ravel J, Gajer P, Abdo Z, Schneider GM, Koenig SS, McCulle SL, et al. Vaginal microbiome of reproductive-age women. Proc Natl Acad Sci U S A. 2011;108 Suppl 1:4680-7.

17. Srinivasan S, Hoffman NG, Morgan MT, Matsen FA, Fiedler TL, Hall RW, et al. Bacterial communities in women with bacterial vaginosis: high resolution phylogenetic analyses reveal relationships of microbiota to clinical criteria. PLoS One. 2012;7(6):e37818. doi:10.1371/journal.pone.0037818.

18. Kim TK, Thomas SM, Ho M, Sharma S, Reich Cl, Frank JA, et al. Heterogeneity of vaginal microbial communities within individuals. J Clin Microbiol. 2009;47:1181-9.

19. Zozaya-Hinchliffe M, Lillis R, Martin DH, Ferris MJ. Quantitative PCR assessments of bacterial species in women with and without bacterial vaginosis. J Clin Microbiol. 2010;48:1812-9.

20. Fredricks DN, Fiedler TL, Thomas KK, Oakley BB, Marrazzo JM. Targeted PCR for detection of vaginal bacteria associated with bacterial vaginosis. J Clin Microbiol. 2007:45:3270-6.

21. Ling Z, Kong J, Liu F, Zhu H, Chen X, Wang Y, et al. Molecular analysis of the diversity of vaginal microbiota associated with bacterial vaginosis. BMC Genomics. 2010;11:488

22. Forsum U, Hallen A, Larsson PG. Bacterial vaginosis-a laboratory and clinical diagnostics enigma. APMIS. 2005;113:153-61.

23. Forsum U, Holst E, Larsson PG, Vasquez A, Jakobsson T, Mattsby-Baltzer I. Bacterial vaginosis-a microbiological and immunological enigma. APMIS. 2005;113:81-90.

24. Larsson PG, Forsum U. Bacterial vaginosis - a disturbed bacterial flora and treatment enigma. APMIS. 2005;113:305-16.

25. Larsson PG, Bergstrom M, Forsum U, Jacobsson B, Strand A, Wolner-Hanssen P. Bacterial vaginosis. Transmission, role in genital tract infection and pregnancy outcome: an enigma. APMIS. 2005;113:233-45.

26. Gardner HL, Dukes CD. Haemophilus vaginalis vaginitis: a newly defined specific infection previously classified non-specific vaginitis. Am J Obstet Gynecol. 1955;69:962-76.

27. Marrazzo JM, Koutsky LA, Eschenbach DA, Agnew K, Stine K, Hillier SL. Characterization of vaginal flora and bacterial vaginosis in women who have sex with women. J Infect Dis. 2002;185:1307-13.

28. Fethers KA, Fairley CK, Morton A, Hocking JS, Fehler G, Kennedy LJ, et al. Low incidence of bacterial vaginosis in cohort of young Australian women. Sex Transm Dis. 2011;38:124.

29. Fethers KA, Fairley CK, Morton A, Hocking JS, Hopkins C, Kennedy LJ, et al. Early sexual experiences and risk factors for bacterial vaginosis. J Infect Dis. 2009;200:1662-70

30. Fethers K, Twin J, Fairley CK, Fowkes FJ, Garland SM, Fehler G, et al. Bacteria vaginosis (BV) candidate bacteria: Associations with BV and behavioural practices in sexually-experienced and inexperienced women. PLoS One 2012;7(2):e30633. doi:10.1371/journal.pone.0030633.

31. Amsel R, Totten PA, Spiegel CA, Chen KC, Eschenbach D, Holmes KK. Nonspecific vaginitis. Diagnostic criteria and microbial and epidemiologic associations. Am J Med. 1983;74:14-22.

32. Muzny CA, Schwebke JR. Suspected heterosexual transmission of bacterial vaginosis without seminal fluid exposure. Sex Transm Dis. 2014;41:58-60.

33. Dawson SG, Ison CA, Csonka G, Easmon CSF. Male carriage of Gardnerella vaginalis. Br J Vener Dis. 1982;58:243-5.

34. Kinghorn GR, Jones BM, Chowdhury FH, Geary I. Balanoposthitis associated with Gardnerella vaginalis infection in men. Br J Vener Dis. 1982;58:127-9.

35. Nelson DE, Dong Q, Pol BVD, Toh E, Fan B, Katz BP, et al. Bacterial communities of the Coronal Sulcus and Distal Urethra of adolescent males. PLoS One. 2012;7(5):e36298. doi:10.1371/journal.pone.0036298.

36. Dong Q, Nelson DE, Toh E, Diao L, Gao X, Fortenberry JD, et al. The microbial communities in male first catch urine are highly similar to those in paired urethral swab specimens. PLoS One. 2011;6(5):e19709. doi:10.1371/journal.pone.0019709.

37. Nelson DE, Van Der Pol B, Dong Q, Revanna KV, Fan B, Easwaran S, et al. Characteristic male urine microbiomes associate with asymptomatic sexually transmitted infection. PLoS One. 2010;5(11):e14116. doi:10.1371/journal. pone.0014116.

38. Price LB, Liu CM, Johnson KE, Aziz M, Lau MK, Bowers J, et al. The effects of circumcision on the penis microbiome. PLoS One. 2010;5(1):e8422. doi:10.1371/journal.pone.0008422.

39. Weng SL, Chiu CM, Lin FM, Huang WC, Liang C, Yang T, et al. Bacterial communities in semen from men of infertile couples: metagenomic sequencing reveals relationships of seminal microbiota to semen quality. PLoS One. 2014;9(10):e110152. doi:10.1371/journal.pone.0110152.

40. Liu CM, Hungate BA, Toblan AAR, Ravel J, Prodger JL, Serwadda D, et al. Penile microbiota and female partner bacterial vaginosis in Rakai, Uganda. MBio. 2015;6(3):e00589-15. doi:10.1128/mBio.00589-15.

41. Eren AM, Zozaya M, Taylor CM, Dowd SE, Martin DH, Ferris MJ. Exploring the diversity of Gardnerella vaginalis in the genitourinary tract microbiota of monogamous couples through subtle nucleotide variation. PLoS One. 2011;6(10):e26732. doi:10.1371/journal.pone.0026732.

42. Liu CM, Hungate BA, Toblan AAR, Serwadda D, Ravel J, Lester R, et al. Male circumcision significantly reduces prevalence and load of genital anaerobic bacteria. MBio. 2013;4(2):e00076-13. doi:10.1128/mBio.00076-13.

43. Gray RH, Kigozi G, Serwadda D, Makumbi F, Nalugoda F, Watya S, et al. The effects of male circumcision on female partners' genital tract symptoms and vaginal infections in a randomized trial in Rakai, Uganda. Am J Obstet Gynecol. 2009;200:42.e1-7. doi:10.1016/j.ajog.2008.07.069.

44. Nugent RP, Krohn MA, Hillier SL. Reliability of diagnosing bacterial vaginosis is improved by a standardized method of gram stain interpretation. J Clin Microbiol. 1991;29:297-301.

45. Eren AM, Ferris MJ, Taylor CM. A framework for analysis of metagenomic sequencing data. Pac Symp Biocomput. 2011;16:131-41. http://psb.stanford. edu/psb-online/proceedings/psb11/eren.pdf.

46. Caporaso JG, Kuczynski J, Stombaugh J, Bittinger K, Bushman FD, Costello EK, et al. QIIME allows analysis of high-throughput community sequencing data. Nat Methods. 2010;7:335-6.

47. Altschul S, Madden T, Schaeffer A, Zhang J, Zhang Z, Miller W, et al. Gapped BLAST and PSI-BLAST: a new generation of protein database search programs. Nucleic Acids Res. 1997;25:3389-402.

48. Fredricks DN, Fiedler TL, Marrazzo JM. Molecular identification of bacteria associated with bacterial vaginosis. N Engl J Med. 2005;353:1899-911.

49. Ferris MJ, Masztal A, Aldridge KE, Fortenberry JD, Fidel PL, Martin DH. Association of Atopobium vaginae, a recently described metronidazole resistant anaerobe, with bacterial vaginosis. BMC Infect Dis. 2004:4:5.

50. Zozaya-Hinchliffe M, Martin DH, Ferris MJ. Prevalence and abundance of uncultivated Megasphaera-like bacteria in the human vaginal environment. Appl Environ Microbiol. 2008;74:1656-9.

51. Zhou X, Bent SJ, Schneider MG, Davis CC, Islam MR, Forney LJ. Characterization of vaginal microbial communities in adult healthy women using cultivation-independent methods. Microbiology. 2004;150:2565-73.

52. Wang Q, Garrity GM, Tiedje JM, Cole JR. Naive Bayesian classifier for rapid assignment of rRNA sequences into the new bacterial taxonomy. Appl Environ Microbiol. 2007;73(16):5261-7.

53. Lozupone C, Knight R. UniFrac: a new phylogenetic method for comparing microbial communities. Appl Environ Microbiol. 2005;71:8228-35.

\section{Submit your next manuscript to BioMed Central and we will help you at every step:}

- We accept pre-submission inquiries

- Our selector tool helps you to find the most relevant journal

- We provide round the clock customer support

- Convenient online submission

- Thorough peer review

- Inclusion in PubMed and all major indexing services

- Maximum visibility for your research

Submit your manuscript at www.biomedcentral.com/submit 